in vivo $34: 3103-3107$ (2020)

doi:10.21873/invivo.12143

Review

\title{
Review of Innovative Physical Therapy Methods: Introduction to the Principles of Cold Physical Plasma
}

\author{
KARSTEN KLETSCHKUS ${ }^{1}$, LYUBOMIR HARALAMBIEV ${ }^{2,3}$, \\ ALEXANDER MUSTEA ${ }^{4}$, SANDER BEKESCHUS ${ }^{5}$ and MATTHIAS B. STOPE ${ }^{1,4}$ \\ ${ }^{1}$ Plasma Oncology Laboratory, Department of Urology, University Medicine Greifswald, Greifswald, Germany; \\ ${ }^{2}$ Department of Trauma, Reconstructive Surgery and Rehabilitation Medicine, \\ University Medicine Greifswald, Greifswald, Germany; \\ ${ }^{3}$ Department of Trauma and Orthopaedic Surgery, \\ $B G$ Klinikum Unfallkrankenhaus Berlin gGmbH, Berlin, Germany; \\ ${ }^{4}$ Department of Gynecology and Gynecological Oncology, University Hospital Bonn, Bonn, Germany; \\ ${ }^{5}$ ZIK plasmatis, Leibniz Institute for Plasma Science and Technology (INP Greifswald), Greifswald, Germany
}

\begin{abstract}
The principles of physics and precision engineering have allowed many technologies to enter standard treatment regimens for a range of diseases. Recently, a new type of technology has been accredited as safe and efficient routine procedure in dermatology in Europe: cold physical plasma. Several accredited devices successfully restrain the powerful energy of plasmas to make them available for therapeutic purposes. Herein, we introduce an introduction to the concept of cold physical plasmas and highlight some fields of their medical applications.
\end{abstract}

In physics, the classical states of matter are gas, liquid, solid, and plasmas. These states can be transformed into one another by changing temperature or pressure. The noble gas argon, for instance, is present at atmospheric pressure and up to a temperature of $83.5 \mathrm{~K}$ as a solid, up to $87.2 \mathrm{~K}$ as liquid, and above this temperature as gas. At even higher temperatures, the atoms reach kinetic energies high enough to separate electrons from their atom. This impact ionization has the effect that with increasing temperature, an increasing

This article is freely accessible online.

Correspondence to: Matthias Stope, Department of Gynecology and Gynecological Oncology, University Hospital Bonn, VenusbergCampus 1, 53127 Bonn, Germany. Tel: +49 22828711361, Fax: +49 22828716091, e-mail: matthias.stope@ukbonn.de

Key Words: Cold plasma, cold atmospheric plasma, physical therapeutic approaches, physics in medicine, review. number of free positive and negative charge carriers are formed. In contrast to slow and positively charged atoms, negative electrons exhibit high kinetic energies and can therefore pass freely between existing atoms. Moreover, the number of separated charge carriers increases with rising temperature. Argon reaches this state above temperatures of about $5,000 \mathrm{~K}$ and then forms a physical plasma $(1,2)$.

In this review, the physical principles of medically applicable cold physical plasmas are presented.

\section{Physical Definition of Plasma}

Some general physical properties are characteristic for plasmas. Due to the free charge carriers, plasma is a good electrical conductor, can be modulated by electric and magnetic fields, but is electrically neutral as a whole. The transmission of electric charges emits electromagnetic radiation. Furthermore, the light and heavy particles in a nonthermal plasma possess different kinetic and thermal energies.

Since gas is neutral overall, it follows that the entirety of separated particles in a plasma are also neutral. The number of positive ions (ni) and negative electrons (ne) in the plasma is, therefore, the same ( $\mathrm{ni}=\mathrm{ne}$ ).

Electrostatic attraction of opposite charges and repulsion of charges of the same polarity leads to the fact that around a charge carrier mainly charge carriers of the other polarity exist. This shields the charge carrier and its electric field. The characteristic shielding length for a plasma, at which the electrostatic field decreases by a factor of $1 / \mathrm{e}$, is defined as the Debye length (3). The Debye length $\left(\lambda_{\text {Debye }}\right)$ is calculated by the following formula, where $\varepsilon_{0}$ is the electrostatic field constant. 


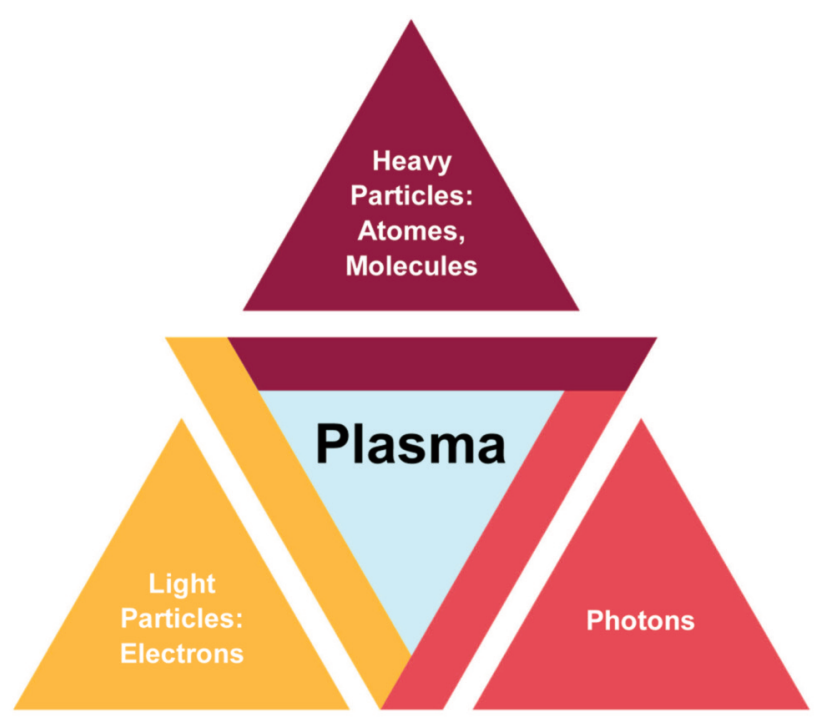

Figure 1. Interactions in plasma.

$\lambda_{\text {Debye }}=\sqrt{\frac{\varepsilon_{0}}{e^{2}} \frac{k_{B} T}{n}}$

$\varepsilon_{0}$ : electrostatic field constant $\left(8,854 \times 10^{-12} \mathrm{C} / \mathrm{Vm}\right) ; \mathrm{k}_{\mathrm{B}}$ : Boltzmann field constant $\left(1,381 \times 10^{-23} \mathrm{~J} / \mathrm{K}\right)$; e: elementary charge $\left(e=1,602 \times 10^{-19} \mathrm{C}\right) ; \mathrm{T}$ : temperature; $\mathrm{n}$ : particle density.

Within the Debye length, one charge carrier binds several charge carriers of the other polarity. In order to have total electrical neutrality within the plasma, the expansion of the plasma $\mathrm{L}_{\text {plasma }}$ must therefore be more than the Debye length.

$$
L_{\text {plasma }}>L_{\text {Debye }}
$$

A spherical space with a radius of one Debye length has the Debye volume. Within this volume there is more than one equally charged particle in a plasma. In order to maintain the overall neutrality of the plasma, significantly more particles must therefore be present in the entire plasma than in a Debye volume, so that all charges are neutral.

$$
N_{\text {total }} \gg N_{\text {Debye volume }}>1
$$

\section{Interactions of Particles Within a Plasma}

Besides heavy positively charged ionized atoms and molecules as well as light electrons, photons with the energy ( $h$ : Planck's constant, and $v$ : frequency of the photon) are also involved in energy transfer within a plasma (Figure 1).

At the transition from an energetically higher to an energetically lower level, energy is emitted in form of photons. This can happen spontaneously and without external influences, or by particle collisions with molecules, atoms, electrons, or photons. Interactions between molecules $(A B)$,

Table I. Clinical and demographic characteristics of patients $(n=33)$.

\begin{tabular}{lcccc}
\hline Element & $\begin{array}{c}\text { Atomic-mass } \\
(\mathrm{g})\end{array}$ & $\begin{array}{c}\text { Ionization } \\
\text { energy }(\mathrm{eV})\end{array}$ & $\begin{array}{c}\text { Ionization } \\
\text { energy }(\mathrm{J})\end{array}$ & $\begin{array}{c}\text { Speed of the } \\
\text { electron for } \\
\text { ionization } \\
(\mathrm{km} / \mathrm{s})\end{array}$ \\
\hline Helium & $6.64 \times 10^{-24}$ & 24.6 & $3.94 \times 10^{-18}$ & 2,940 \\
Neon & $3.35 \times 10^{-23}$ & 21.6 & $3.46 \times 10^{-18}$ & 2,750 \\
Argon & $6.62 \times 10^{-23}$ & 15.8 & $2.53 \times 10^{-18}$ & 2,350 \\
Nitrogen & $2.32 \times 10^{-23}$ & 14.5 & $2.32 \times 10^{-18}$ & 2,250 \\
Oxygen & $2.66 \times 10^{-23}$ & 13.6 & $2.18 \times 10^{-18}$ & 2,180 \\
Hydrogen & $1.67 \times 10^{-24}$ & 13.6 & $2.18 \times 10^{-18}$ & 2,180 \\
\hline
\end{tabular}

atoms $\left(A, B, A^{*}\right.$ excited atom), electrons $\left(e-, e^{-}\right)$, and photons $(h v)$ in plasma can be described by the following effects:

- impact ionization

- addition and dissociation

- excitation impulses

- photoionization

- photoemission

\section{Technical Production of Cold Plasma}

For the technical generation of plasmas, electrons are accelerated in an electric or electromagnetic field. The electrons are already present in the atmosphere or can be emitted from a cathode by applying a high voltage (4). The free electrons are then accelerated in an electric field so that their kinetic energy is sufficient to ionize atoms by impact ionization (Table I).

$E_{\text {kin }}=E_{\text {pot }}$

$\frac{1}{2} m_{e} v_{e}^{2}=e U$

$v_{e}=\sqrt{\frac{2 e}{m_{e}} U}$

$E_{\text {kin }}:$ kinetic energy of the electron; $E_{\text {pot }}$ : potential energy of the electron in the electric field; $m_{\mathrm{e}}$ : electron mass $9.109 \times 10^{-31} \mathrm{~kg} ; v_{e}$ : electron velocity; $U$ : voltage difference that the electron experiences in the electric field

The first ionizing impact increases the number of charged particles from one electron to two electrons and one ionized atom. The charged particles are further accelerated in the electric field, causing repeated collisions with other atoms and thus the release of more charged particles. As a result, the number of free electrons and ionized atoms increases avalanche-like (Figure 2). In these collisions, however, very little kinetic energy is transferred from the electrons to the atoms, since the difference in mass between the two particle 


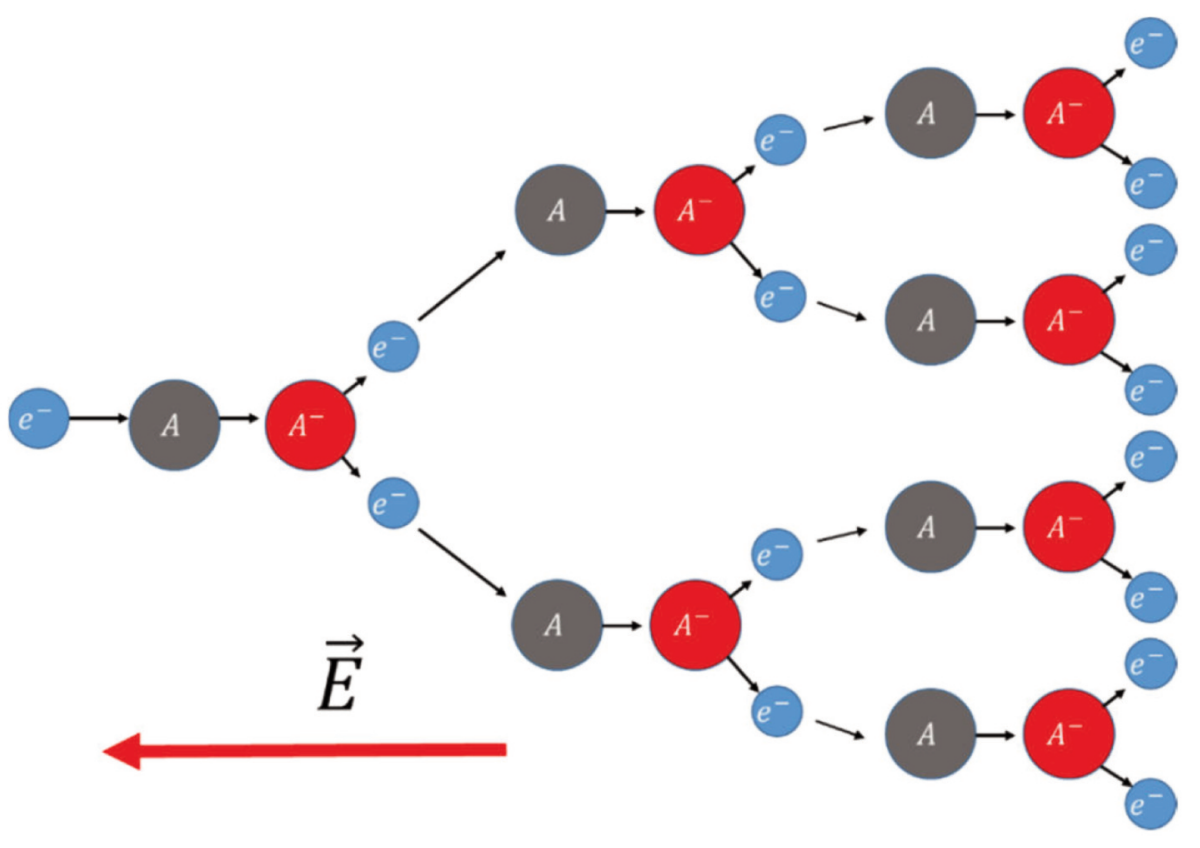

Figure 2. Initial avalanche of plasma in the electric field generated by impact ionization.

species is very high. In argon, for example, the mass ratio of an electron to an atom is about 1:73,250. This small transfer of kinetic energy to the ionized atoms is the reason why the overall temperature in cold plasmas remains comparatively low.

The field strength of the electric field is decisive for the kinetic energy of an electron. In addition, the free length of path that the electron travels until collision is important. This depends on the distance between the particles in the plasma. If the free length of path between two collisions is too short, the electron cannot be accelerated sufficiently and has only minimal kinetic energy. On the other hand, if the free length of path is too long, the number of collisions is too small, and there are not enough free charge carriers. The mean free length of path in the plasma depends on the particle density and, thus, on the pressure in the plasma and the diameters of the collision partners (5).

For the atom-electron collision in an argon plasma generated with a microwave field of $2.5 \mathrm{GHz}$, the mean free length of path have been determined (Table II) (6). In alternating fields, the reversal of the field direction leads to a deceleration of the electrons. Due to the high kinetic energy of the electrons, however, this can be ignored since, in the time between two changes of the field direction, a multiple of the free length of path is covered, and collisions occur frequently.

To obtain cold plasma, the plasma must be generated with a high-frequency alternating field. Under these conditions, the time required to accelerate the electrons and to collide with
Table II. Clinical and demographic characteristics of patients $(n=33)$.

\begin{tabular}{lccc}
\hline $\begin{array}{l}\text { Particle } \\
\text { density }(\mathrm{m})\end{array}$ & $\begin{array}{c}\text { Pressure } \\
(\mathrm{pa})\end{array}$ & $\begin{array}{c}\text { Pressure } \\
\text { (bar) }\end{array}$ & $\begin{array}{c}\text { Mean free path } \\
\text { length }(\mathrm{m})\end{array}$ \\
\hline $2.41 \times 10^{24}$ & $1.0 \times 10^{2}$ & 0.001 & $2.6 \times 10^{-3}$ \\
$2.41 \times 10^{25}$ & $1.0 \times 10^{5}$ & 1.0 & $2.6 \times 10^{-6}$ \\
$1.21 \times 10^{27}$ & $5.0 \times 10^{6}$ & 50.0 & $5.2 \times 10^{-8}$ \\
$4.83 \times 10^{27}$ & $2.0 \times 10^{7}$ & 200.0 & $1.3 \times 10^{-8}$ \\
\hline
\end{tabular}

atoms is too short for a significant transfer of kinetic energy from the free electrons to the atoms to occur (7). These cold plasmas are therefore also called non-equilibrium plasmas.

\section{Cold Atmospheric Plasma}

The development of cold plasma devices was essential for medical applications because only plasma with a temperature only slightly above body temperature can be used safely and without harm to human patients. A second prerequisite was the development and optimization of devices whose plasmas ignite in the normal ambient atmosphere. Special ambient conditions under vacuum or inert gas atmosphere as in physical experimental setups cannot be used in clinical practice. Such plasma devices are often operated with the carrier gas argon or helium and are called atmospheric or atmospheric pressure plasma (8). A special property of these 
plasmas is the interaction of particles at the argon/helium plasma interface with the atmosphere. Also in this case an energy transfer takes place, and numerous reactive oxygen (ROS) and nitrogen species (RNS) are being formed with oxygen and nitrogen of the ambient air. These contribute significantly to the biological effects observed with the application of cold plasmas and are the subject of extensive studies in experimental plasma medicine $(9,10)$.

\section{Plasma in Medicine}

In industry, the use of plasma is widespread (11-13). Since the early 1990s, research has increasingly been undertaken at the interface between physics and the life sciences in order to characterize the biological effects of cold plasma and to identify new areas of application for medical use $(14,15)$. Until now, cold plasma has been used in hygiene to sterilize surgical instruments, implants and other mainly thermally sensitive materials (16-18). Furthermore, cold plasma is also approved for the treatment of dermatological diseases and is used with great success, particularly in the treatment of chronic wounds $(19,20)$. Other areas of application in surgery, oncology, and dentistry are the subject of current investigations and point to some very promising possibilities.

The biological effects are manifold and far from being fully understood. In addition to electromagnetic radiation, ROS and RNS appear to be essential inductors of biological cell responses. Disturbances of cell membrane functions and the activation of cellular redox systems lead to serious impairments in cellular physiology and regulation $(21,22)$, which ultimately spurs the induction of programmed cell death (apoptosis) (23). Cold plasma is therefore highly suitable for the inactivation of neoplastic and malignant cells as well as the reduction of pathogens.

Despite numerous studies, there is no evidence of a mutagenic and carcinogenic effect of cold plasma (24-26). Therefore, the use of plasma - by itself or in combination with established therapies - seems to be a promising and innovative extension of medical opportunities. Similar to other novel physical procedures, the devices have to be adapted to medical requirements and constantly developed further. Currently, there are already 4 cold plasma devices with approved safety for medical use on the market (kINPen MED - neoplas tools, Greifswald, Germany; SteriPlas Adtec Healthcare, Hounslow, United Kingdom; PlasmaDerm - CINOGY System, Duderstadt, Germany; PlasmaCare Terraplasma Medical, Garching, Germany), and further approvals are expected.

\section{Conclusion}

The development of high-frequency devices for the formation of cold plasmas, i.e. plasmas with temperatures only slightly above body temperature, opens the way for another physical treatment method to enter the field of medicine. Current data show promising application horizons for cold plasma technology in dermatology, dentistry and oncology, and further areas of application can certainly be expected.

\section{Conflicts of Interest}

The Authors have no conflicts of interest to declare.

\section{Authors' Contributions}

KK: Layout of the illustrations, writing the manuscript; LH: Layout of the illustrations; AM: writing the manuscript, copyediting; SB: writing the manuscript; MBS: writing the manuscript.

\section{Acknowledgements}

The Authors would like to thank Lena Zeyda for her critical revision of the manuscript.

\section{References}

1 Trelles JP, Heberlein JVR and Pfender E: Non-equilibrium modelling of Arc plasma torches. J Phys D Appl Phys 40: 5937, 2007. DOI: $10.1088 / 0022-3727 / 40 / 19 / 024$

2 Kanhe NS, Tak AK, Bhoraskar SV, Mathe VL and Das AK: Transport properties of Ar-Al plasma at 1 atmosphere. AIP Conference Proc 1447: 1025, 2012. DOI: 10.1063/1.4710355

3 Stroth U: Plasmaphysik: Phänomene, Grundlagen, Anwendungen. First edition. Heidelberg, Berlin, Springer Verlag, pp 13-40, 2011

4 Demtröder W: Experimentalphysik 2: Elektrizität und Optik. Seventh edition. Heidelberg, Berlin, Springer Verlag, pp 42-47, 2005.

5 Hübner S, Hofmann S, van Veldhuizen EM and Bruggeman PJ: Electron densities and energies of a guided argon streamer in argon and air environments. Plasma Sources Sci Technol 22: 65011, 2013. DOI: 10.1088/0963-0252/22/6/065011

6 Heuermann H: Mikrowellen-technik. pp 201-204, 2015. Available at: http://www.hhft.de/files/competences/ Mikrowellentechnik_von_Prof_Heuermann_V1_5.pdf

7 Fridman A: Plasma Chemistry, First edition. New York, Cambridge University Press, 132-138, 2008.

8 Kong MG, Kroesen G, Morfill G, Nosenko T, Shimizu T, van Dijk J and Zimmermann JL: Plasma medicine: An introductory review. New J Phys 11: 115012, 2009. DOI: 10.1088/13672630/11/11/115012

9 Woedtke T, Schmidt A, Bekeschus S, Wende K and Weltmann KD: Plasma medicine: A field of applied redox biology. In Vivo 33: 1011-1026, 2019. PMID: 31280189. DOI: 10.21873/invivo.11570

10 Privat-Maldonado A, Schmidt A, Lin A, Weltmann KD, Wende K, Bogaerts A and Bekeschus S: ROS from physical plasmas: Redox chemistry for biomedical therapy. Oxid Med Cell Longev 2019: 9062098, 2019. PMID: 31687089. DOI: 10.1155/2019/9062098

11 Kerspe JH: Aufgaben und Verfahren in der Oberflächenbehandlung. First edition. Tübingen, Expert Verlag Gmbh, pp 78-104, 2000.

12 Laroussi M, Kong M, Morfill M and Stolz W: Plasma medicine - Applications of low-temperature gas plasmas in medicine and 
biology. First edition. New York, Cambridge University Press, pp 156-174, 2012.

13 Daeschlein G: Plasma-Medizin - Neue Wege der Haut-, Wundund Krebsbehandlung in Theorie und Praxis, First edition. Bremen, Uni-Med Verlag AG, pp 16-21, 2017.

14 Toyokuni S, Ikehara Y, Kikkawa F and Hori M: Plasma medical science. First edition. Academic Press, London, pp 279-285, 2018.

15 Gümbel D, Bekeschus S, Gelbrich N, Napp M, Ekkernkamp A, Kramer A and Stope MB: Cold atmospheric plasma in the treatment of osteosarcoma. Int J Mol Sci 2917: 18, 2017. PMID: 28925941. DOI: 10.3390/ijms 18092004

16 Kramer A, Bekeschus S, Matthes R, Bender C, Stope MB, Napp M, Lademann O, Lademann J, Weltmann KD and Schauer F: Cold physical plasmas in the field of hygiene - Relevance, significance, and future applications. Plasma Process Polym 12: 1410-1422, 2015. DOI: 10.1002/ppap.201500170

17 Raguse M, Fiebrandt M, Denis B, Stapelmann K, Eichenberger P, Driks A, Eaton P, Awakowicz P and Moeller R: Understanding of the importance of the spore coat structure and pigmentation in the Bacillus subtilis spore resistance to low-pressure plasma sterilization. J Phys D Appl Phys 49: 285401, 2016. DOI: 10.1088/0022-3727/49/28/285401

18 Coelho PG, Giro G, Teixeira HS, Marin C, Witek I, van Thompson P, Tovar N and Silva NRFA: Argon-based atmospheric pressure plasma enhances early bone response to rough titanium surfaces. J Biomed Mater Res A 100: 1901-1906, 2012. PMID: 22492543. DOI: 10.1002/jbm.a.34127

19 Daeschlein G, Napp M, Lutze S, Arnold A, von Podewils S, Gümbel D and Jünger M: Skin and wound decontamination of multidrug-resistant bacteria by cold atmospheric plasma coagulation. J Dtsch Dermatol Ges 13: 143-150, 2015. PMID: 25597338. DOI: $10.1111 /$ ddg.12559

20 Bernhardt T, Semmler ML, Schafer M, Bekeschus S, Emmert S and Boeckmann L: Plasma medicine: Applications of cold atmospheric pressure plasma in dermatology. Oxid Med Cell Longev 2019: 3873928, 2019. PMID: 31565150. DOI: 10.1155/ 2019/3873928
21 Weiss M, Gümbel D, Hanschmann EM, Mandelkow R, Gelbrich N, Zimmermann U, Walther R, Ekkernkamp A, Sckell A, Kramer A, Burchardt M, Lillig CH and Stope MB: Cold atmospheric plasma treatment induces anti-proliferative effects in prostate cancer cells by redox and apoptotic signaling pathways. PLoS One 10: e0130350, 2015. PMID: 26132846. DOI: 10.1371 /journal.pone.0130350

22 Haralambiev L, Nitsch A, Jacoby JM, Strakeljahn S, Bekeschus S, Mustea A, Ekkernkamp A and Stope MB: Cold atmospheric plasma treatment of chondrosarcoma cells affects proliferation and cell membrane permeability. Int J Mol Sci 21: 21, 2020. PMID: 32225067. DOI: 10.3390/ijms21072291

23 Bekeschus S, Schütz CS, Niessner F, Wende K, Weltmann KD, Gelbrich N, Woedtke T, Schmidt A and Stope MB: Elevated $\mathrm{H} 2 \mathrm{AX}$ phosphorylation observed with kINPen plasma treatment is not caused by ROS-mediated DNA damage but is the consequence of apoptosis. Oxid Med Cell Longev 2019: 8535163, 2019. PMID: 31641425. DOI: 10.1155/2019/8535163

24 Bekeschus S, Schmidt A, Kramer A, Metelmann HR, Adler F, Woedtke T, Niessner F, Weltmann KD and Wende K: High throughput image cytometry micronucleus assay to investigate the presence or absence of mutagenic effects of cold physical plasma. Environ Mol Mutagen 59: 268-277, 2018. PMID: 29417643. DOI: 10.1002/em.22172

25 Schmidt A, Woedtke T, Stenzel J, Lindner T, Polei S, Vollmar B and Bekeschus S: One year follow-up risk assessment in SKH-1 mice and wounds treated with an argon plasma jet. Int J Mol Sci 2017: 18, 2017. PMID: 28422070. DOI: 10.3390/ijms18040868

26 Kluge S, Bekeschus S, Bender C, Benkhai H, Sckell A,Below H, Stope MB and Kramer A: Investigating the mutagenicity of a cold argon-plasma jet in an HET-MN model. PLoS One 11: e0160667, 2016. PMID: 27584003. DOI: 10.1371/journal.pone.0160667

Received June 6, 2020

Revised August 21, 2020

Accepted August 23, 2020 